Abstracta Iranica

Revue bibliographique pour le domaine irano-aryen

Volume 32-33 | 2013

Comptes rendus des publications de 2009-2010

\title{
Sajjad H. Rizvi. Mīr Dāmād and the debate on Hudūt $-i$ dahrī in India
}

\section{Mathieu Terrier}

\section{(2) OpenEdition}

1 Journals

\section{Édition électronique}

URL : http://journals.openedition.org/abstractairanica/40539

DOI : 10.4000/abstractairanica.40539

ISSN : 1961-960X

Éditeur :

CNRS (UMR 7528 Mondes iraniens et indiens), Éditions de l'IFRI

\section{Édition imprimée}

Date de publication : 1 décembre 2013

ISSN : 0240-8910

Référence électronique

Mathieu Terrier, "Sajjad H. Rizvi. Mīr Dāmād and the debate on Ḥudūț-i dahrī in India », Abstracta Iranica [En ligne], Volume 32-33 | 2013, document 391, mis en ligne le 01 juillet 2016, consulté le 05 octobre 2020. URL : http://journals.openedition.org/abstractairanica/40539 ; DOI : https://doi.org/ 10.4000/abstractairanica.40539

Ce document a été généré automatiquement le 5 octobre 2020.

Tous droits réservés 


\title{
Sajjad H. Rizvi. Mīr Dāmād and the debate on Hudūt-i dahrī in India
}

\author{
Mathieu Terrier
}




\section{RÉFÉRENCE}

Sajjad H. Rizvi. « Mīr Dāmād and the debate on Hudūt-i dahrī in India », in : Denis Hermann and Fabrizio Speziale, eds., Muslim cultures in the Indo-Iranian World during the Early-Modern and Modern Periods. Berlin, IFRI/Klaus Schwarz Verlag, 2010, p. 449-473.

Le programme de la madrasa indienne aux XVIII ${ }^{\mathrm{e}}$ et XIX ${ }^{\mathrm{e}}$ siècles intègre en bonne place les systèmes des philosophes iraniens Mīr Dāmād (m. 1041/1631) et de Mullā Ṣadrā (m. 1045/1635). L'article se concentre sur l'influence du premier, promoteur d'une "philosophie yéménite» qui conjugue les héritages de la raison grecque et de la prophétie arabe, dont le principal apport conceptuel est la «création perpétuelle » (en persan hudūt $-i$ dahrī), fondée sur un commentaire critique d'Avicenne. Il s'agit de penser un niveau ontologique, celui du dahr, intermédiaire entre le temps naturel (zamā $n$ ) et l'éternité pure de l'essence divine (sarmad), pour échapper aux apories du débat sur l'éternité du monde. Mullā Mahmūd Jaunpūrī (m. 1652), chef de file des philosophes indiens au XVII ${ }^{\mathrm{e}}$ s., qui pourrait avoir été un temps l'élève de Mīr Dāmād, diffuse la théorie de celui-ci dans son ouvrage intitulé Al-Šams al-bālig̉a. Si Jaunpūrī se situe dans la tradition de la «philosophie yéménite », il n'en critique pas moins le concept de « création perpétuelle » et les positions rigoureusement aristotéliciennes du maître. Les débats entraînés en Inde par le concept de création perpétuelle sont d'autant plus signifiants que cette innovation philosophique a suscité peu d'intérêt en Iran, où la philosophie de Mīr Dāmād a été éclipsée par celle de son brillant élève Mullā Ṣadrā et son concept de mouvement intra-substantiel (en arabe harakat jawhariyya). En conclusion, la renaissance philosophique connue à Delhi au XIX ${ }^{\mathrm{e}} \mathrm{s}$. doit beaucoup à la philosophie iranienne chiite de la première moitié du XVII ${ }^{\mathrm{e}}$ et à son grand maître injustement oublié, Mīr Dāmād.

\section{AUTEURS}

\section{MATHIEU TERRIER}

Paris 